\title{
O ensino de Sociologia com o PBworks: Do espaço de trabalho ao protagonismo dos estudantes no aprendizado
}

\author{
Patrick Oliveira Silveira - UFRN - patrick.silveira@ufrgs.br
}

\begin{abstract}
Resumo: Neste texto é apresentada a experiência da criação de um espaço de trabalho para a disciplina de Sociologia no PBworks como complemento às aulas presenciais, numa escola da rede estadual do Rio Grande do Sul, em Porto Alegre. Inicialmente o professor estagiário criou o espaço para a disciplina e posteriormente solicitou que cada grupo de estudantes desenvolvesse seu próprio espaço, com suas pesquisas, textos, e postasse o link no espaço da disciplina. O principal objetivo foi apresentar o PBworks e proporcionar aos estudantes a oportunidade de trabalhar de forma colaborativa, tornando-os protagonistas de sua própria aprendizagem. A pesquisa consistiu em quatro etapas: apresentação do espaço criado para a disciplina pelo professor estagiário e o cadastro e familiarização dos estudantes no mesmo; o desenvolvimento das pesquisas e dos espaços dos estudantes; a avaliação do uso do PBworks pelos estudantes, professor estagiário e professora regente; e finalmente, a escrita do relatório sobre a pesquisa que deu origem a este artigo. $\mathrm{O}$ resultado dessa experiência foi bastante positivo, já que, a partir da avaliação dos envolvidos na pesquisa, foi decidido que o espaço de trabalho seria adotado de forma permanente como ferramenta complementar às aulas de Sociologia daquela instituição.
\end{abstract}

Palavras-chave: ciberespaço, pbworks, sociologia.

\section{Teaching Sociology with PBworks: From workspace to the protagonism of students in learning}

\begin{abstract}
This paper presents the experience from creation a workspace for the discipline of Sociology in PBworks as a complement to regular classes in a state school of Rio Grande do Sul in Porto Alegre. Initially the trainee teacher created the space for the discipline and subsequently requested that each group of students to develop their own space with their research, texts, and post the link on space from discipline. The main objective was to present the PBworks and give students the opportunity to work collaboratively, making them the protagonists of their own learning. The research consisted of four stages: presentation of the space created for the discipline by the trainee teacher and the registration and familiarization of students in the same; the development of research and spaces for students; evaluating the use of PBworks by students, teacher trainee, conductor teacher; and finally, report writing about the research that led to this article. The result of this experience was very positive, since, from the evaluation of those involved in the research, it was decided that the workspace would be adopted on a permanent basis as a complementary tool to sociology classes that institution.
\end{abstract}

Keywords: cyberspace, pbworks, sociology.

\section{Introdução}


O retorno do ensino de Sociologia aos currículos da educação básica acontece num momento de grandes modificações na sociedade contemporânea, principalmente na forma de como os indivíduos interagem entre si. Além da comunicação direta e presencial acrescenta-se a maneira virtual, por meio de interfaces de dispositivos computacionais e o avanço de recursos tecnológicos. Contudo essas mudanças nem sempre ocorrem nas salas de aulas escolares, porque alguns professores resistem ao uso dessa tecnologia, por se sentirem mais seguros na manutenção da tradição de ensino presencial, evitando entrar no mundo desconhecido do aprendizado em conjunto dos dispositivos e recursos computacionais.

Segundo as Orientações Curriculares Nacionais (OCN's) para o ensino médio, o ensino de Sociologia inicia por intermédio de Émile Durkheim na Universidade de Boudeaux, em 1887, e o ingresso da disciplina nos currículos oficiais. No Brasil a entrada da disciplina de Sociologia acontece pela primeira vez na reforma Rocha Vaz em 1925. Anteriormente, em 1870, Rui Barbosa propôs a entrada da disciplina no lugar da de Direito Natural. Segundo (Meirelles et. al., 2012) um dos grandes intelectuais da Sociologia brasileira, o professor Florestan Fernandes, defende a sua importância na educação básica por a disciplina poder ajudar no desenvolvimento do Brasil e de seu povo no despertar a consciência dos seus direitos, da sua cidadania, do seu aspecto profissional em benefício de toda a sociedade. A partir da primeira Lei de Diretrizes e Bases da Educação - LDB (Lei nº 4.024/61) a disciplina transita pelos currículos da educação básica, porque a legislação a coloca em caráter opcional. Na segunda LDB (Lei nº5.692/71), durante o período militar, ela é retirada dos currículos e no seu lugar entram as disciplinas Educação Moral e Cívica (EMC) e Organização Social e Política Brasileira (OSPB). Com a reabertura política na década de 1980 e da lei no 7.044/82 a Sociologia vagarosamente volta a figurar nos currículos escolares. Na LDB de 1996 consta que os estudantes deveriam sair com conhecimentos em Sociologia para habilitálos ao mundo do trabalho, a evolução como individuo e o exercício de sua cidadania. A partir da luta e mobilizações de associações, cientistas, intelectuais, movimentos sociais e sindicatos pela incorporação obrigatória da disciplina, esta é aprovada pelo colegiado da Câmara de Educação Básica - CEB e do Conselho Nacional de Educação- CNE no parecer CNE/CEB no 38/2006.

Este trabalho baseia-se numa análise sobre o estudo de caso qualitativo, de uma experiência de prática de estágio docente, realizada no segundo semestre de 2015, com a criação de um espaço de trabalho no PBworks na disciplina de Sociologia, para duas turmas de ensino médio, da Escola Estadual Francisco Antônio Vieira de Caldas Júnior, mais conhecida como "Caju" em Porto Alegre. Foram analisados os benefícios que a ferramenta proporcionou, a partir da transposição didática dos conteúdos e materiais do meio físico para o digital, e as dificuldades enfrentadas durante o transcorrer das aulas de Sociologia.

\section{Métodos de análise do espaço no PBworks nas aulas}

Bem difundido no meio acadêmico, o PBworks é uma ferramenta de criação de páginas ou espaços de trabalho abertos ou fechados de fácil elaboração e edição de hipertextos, inserção de imagens, links, tabelas e outros recursos disponíveis na constituição desses, sem a necessidade do usuário ter grande domínio de linguagens de 
programação. O que o diferencia dos Ambientes Virtuais de Aprendizagem (AVA) é de ser uma ferramenta Wiki de construção e edição em tempo real e colaborativa dos usuários, assim como a enciclopédia OnLine Wikipédia. Além dessas características, possui uma capacidade de armazenamento de arquivos que pode chegar a 2 gigabytes (GB) de forma gratuita, o que determinou a escolha desta ferramenta, em detrimento de Blogs e FanPages, para o trabalho com Sociologia na escola. Porém, ele exige conhecimento de inglês básico para a sua operação.

Algumas experiências de ensino com o PBworks já foram realizadas por (Bona e Basso, 2010) na elaboração de portfólios de Matemática e por (Seib, 2010) nos anos iniciais do ensino fundamental. No ensino de Sociologia temos os espaços abertos criados por Batista ${ }^{1}$, Galassi $^{2}$ e Mello ${ }^{3}$ voltados a disciplinas do ensino superior, auxílio de recursos e materiais para as aulas e formação de professores respectivamente. Já no ensino médio não foram encontrados espaços abertos até então, mas devido a opção existente no PBworks de se fazer espaços privados, podem existir mais destes voltados a disciplina, como relato no meu Trabalho de Conclusão de Licenciatura em Ciências Sociais - TCL $^{4}$ (Silveira, 2015).

Um objetivo importante do trabalho foi investigar se o uso deste espaço virtual contribuiu para o aperfeiçoamento do estudo de Sociologia pelos estudantes, também em suas residências, já que a disciplina de Sociologia conta com apenas um período semanal. O espaço foi mantido privado, acessível só para as turmas envolvidas no trabalho, para proporcionar maior liberdade de expressão aos estudantes sobre os assuntos trabalhados na disciplina, para proteger suas produções intelectuais e suas identidades já que a maioria dos envolvidos era menor de idade.

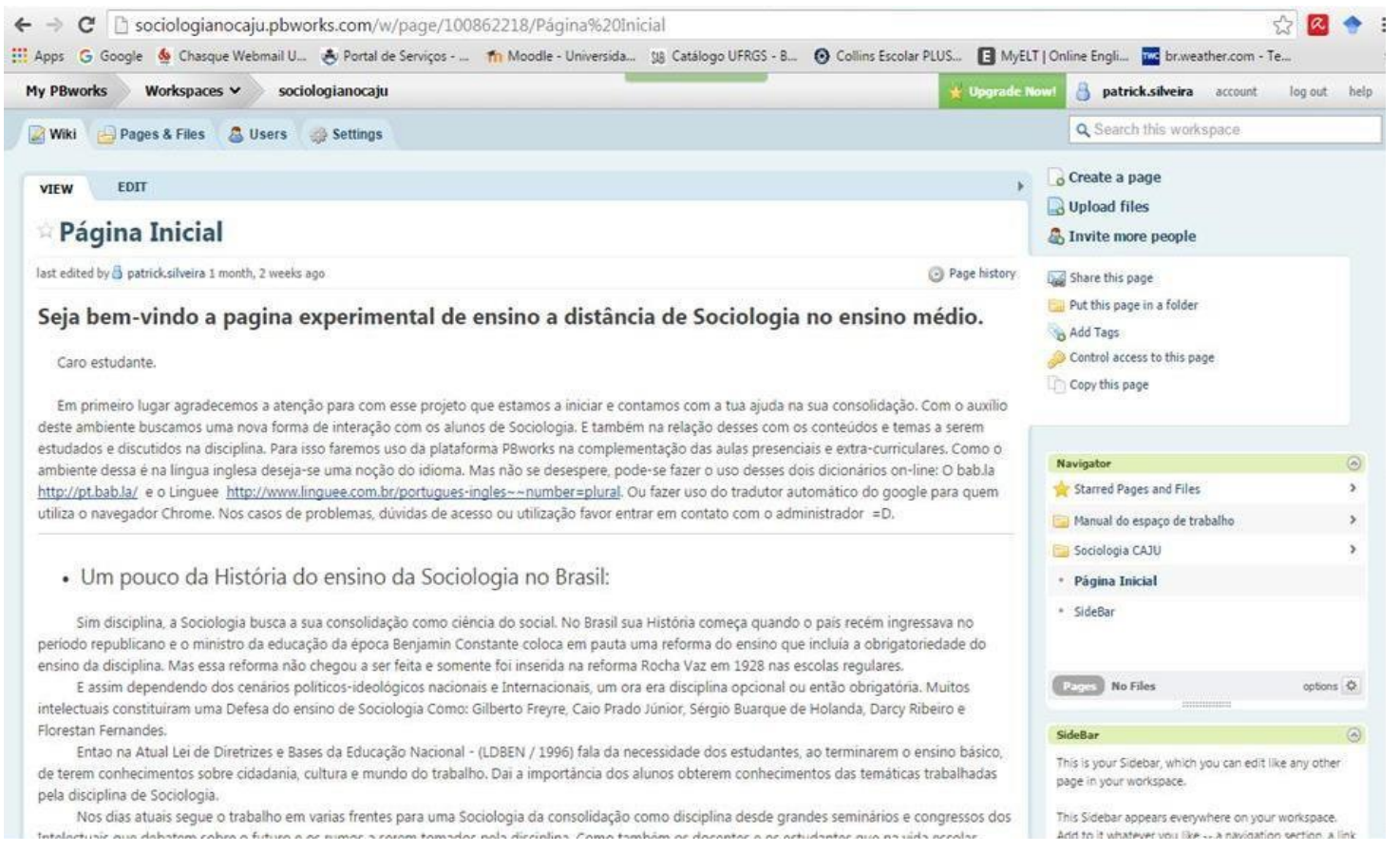

\section{Imagem 1 - Página inicial "FrontPage" do espaço de trabalho no PBworks.}

\footnotetext{
${ }^{1}$ Neusa Chaves Batista, Doutora em Educação pela UFRGS.

${ }^{2}$ Claudia Simone Galassi, Mestra pela UNESP.

${ }^{3}$ Rosângela Menta Mello, Graduada em Pedagogia pela Universidade Estadual de Ponta Grossa, estado do Paraná.

${ }^{4}$ TCL orientado pelo professor Dr. Leandro Raizer, Doutor em Sociologia pela UFRGS, Professor adjunto na FACED - UFRGS.
} 
$\mathrm{Na}$ contemporaneidade os jovens interagem de diversas formas, por meio físico na escola e em sala com os demais estudantes, e por meio virtual, através dos mais diferentes dispositivos tecnológicos, sendo mais utilizado o telefone celular com acesso a rede móvel de dados, mas também são usados os computadores de mesa e os notebooks. Para (Castells, 2012), os jovens participariam de várias comunidades ou sociedades em rede segundo suas escolhas e estratégias como atores sociais. O que me remete a (Latour, 2012) sobre a teoria do ator rede, nas ações que eles praticam ao utilizar os dispositivos informacionais e como elas refletem nas suas relações sociais dentro e fora do ciberespaço. Esses momentos são percebidos como oportunidades que os docentes têm de aproveitar as habilidades dos estudantes no uso das tecnologias e canalizá-las para o seu aprendizado, com o espaço de trabalho acessível pela internet em qualquer lugar no tempo e no espaço (Lévy, 1999). Nesse contexto, o professor terá de superar várias barreiras para conseguir, de fato, implementar alguma ferramenta tecnológica, ainda mais em escolas públicas, como a envolvida no estudo, que geralmente carecem de equipamentos e quando os possuem, falta manutenção nesses e nos laboratórios de informática. Em alguns estabelecimentos de ensino existem resistências de parte do quadro docente ao uso dessas tecnologias. Os motivos vão desde a insegurança e a falta de preparo no manuseio delas, devido a pouca ou nenhuma prática durante a formação; ao comodismo de ficar apegado à uma sensação "segurança" de uma aula tradicional sem grandes mudanças na forma de ensino do que se aventurar no desconhecido mundo digital. Como defende (Kuhn, 2001) é preciso superar o paradigma velho, como no caso investigado o pensamento educacional vigente e através de novos conceitos e na revisão de métodos e aplicações científicas, pensar num ensino que contemple o professor como orientador dos estudantes na busca dos conhecimentos sociológicos junto ao universo digital. Para isso é fundamentar que o docente conheça seus estudantes, principalmente na hora de preparar as aulas de Sociologia e outras disciplinas.

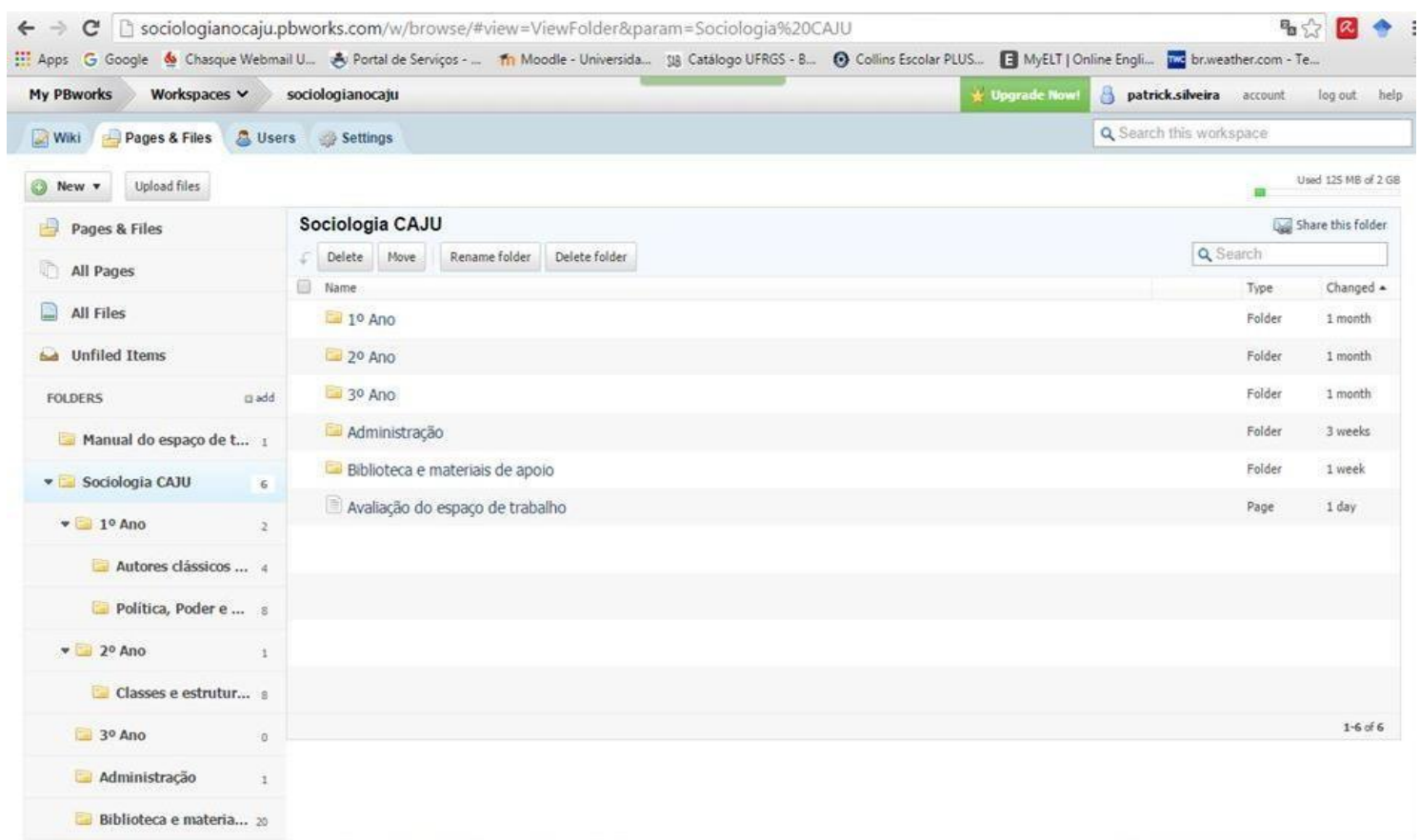

Imagem 2 - O conteúdo da pasta Sociologia caju. 
A primeira etapa da pesquisa consistiu em combinações do estagiário com os estudantes em relação à dinâmica das aulas, ao cadastro no espaço de trabalho e às avaliações, No período de uma semana, entre uma aula e outra, foi observado que poucos estudantes tiveram a iniciativa de olhar o espaço de trabalho antes da segunda aula. Ao chegar o dia da segunda aula, constatou-se que a maior parte dos estudantes não sabia o que fazer após clicar no link enviado pelo cadastro automático do PBworks; outros nem sequer chegaram a ver o e-mail explicativo, na caixa de correio eletrônico. Nos primeiros minutos de aula, o estagiário docente teve de auxiliar os estudantes a realizar o cadastro no PBworks e ingressar no espaço de trabalho da disciplina. Superadas as dificuldades de acesso pela maioria dos educandos, foi dada como tarefa inicial a visualização de um vídeo e a leitura de um hipertexto produzido e postado pelo professor estagiário. Os estudantes deveriam escrever comentários sobre o material postado na caixa de diálogo reservada para tal. A aula transcorreu bem com alguns estudantes interagindo através dos comentários no espaço e pessoalmente, no término da aula e todos saíram satisfeitos do laboratório. Depois de sanadas as dificuldades pontuais (falta de acesso dos estudantes ao espaço por falta de cadastro ou dificuldade no idioma inglês) as aulas transcorreram normalmente com nova interação entre os estudantes no espaço.

A segunda etapa da pesquisa ocorreu a partir reflexão feita pelo professor estagiário sob sua proposta inicial, e posteriormente considerou que houve apenas uma troca de recursos materiais para virtuais no ensino de Sociologia. A lousa foi meramente substituída pela tela, o giz pela caneta, e os livros impressos pelo hipertexto, imagens, vídeos, e-books e demais materiais digitais. O docente percebeu que os estudantes ficavam conversando entre si no laboratório ou interagindo em redes sociais como o Facebook, deixando de lado o espaço de trabalho, por isso, considerou importante introduzir uma proposta que exigisse mais protagonismo, onde os estudantes trabalhassem de forma colaborativa. Para tal, propôs temas a desenvolver em grupos, nos quais os estudantes tiveram que elaborar seus próprios espaços de trabalhos e postar o link no espaço de trabalho da disciplina, como parte da avaliação. Isso resultou numa maior mobilização para conhecer a ferramenta e pesquisar a fundo os temas pelos quais ficaram responsáveis. A partir dessa proposta, foi criado, dentro do espaço de trabalho inicial da disciplina, um banco de espaços de trabalho dos estudantes de Sociologia, algo semelhante aos portfólios pesquisados por (Bona e Basso, 2010). Nessa experiência, diferente das aulas tradicionais, os estudantes tiveram que primeiramente buscar abastecer-se de conhecimento e informações sobre o tema a ser investigado por eles mesmos, e posteriormente, com a ajuda do docente, familiarizar-se com os recursos fornecidos pelo PBworks, tornando-se os atores principais na interiorização e exteriorização dos próprios conhecimentos.

A terceira etapa da pesquisa foi a avaliação do uso dessa ferramenta por todos os envolvidos no trabalho: professor estagiário, estudantes de Ensino Médio e professora regente da disciplina ${ }^{5}$. A partir de um debate em aula e de um questionário no próprio espaço virtual, o grupo concluiu que essa ferramenta foi um complemento importante para as aulas presenciais e que possibilitou o desenvolvimento de autonomia e colaboração entre os estudantes. Por esses motivos decidiram pela permanência do PBworks nas aulas de Sociologia dos próximos anos na instituição. A quarta etapa da pesquisa foi à escrita do relatório que deu origem ao TCL de (Silveira, 2015) e a este artigo.

\footnotetext{
${ }^{5}$ Professora Sara Mendes, Licenciada em História pela Faculdade Porto-Alegrense - FAPA
} 


\section{O confronto das expectativas com os resultados obtidos}

Antes de iniciar a experiência com o espaço de trabalho no PBworks esperavamse dificuldades com relação à infra-estrutura do laboratório de informática da escola porque o estagiário docente constatou limitações nos equipamentos e redes de informática da escola, durante o período de observação das aulas da disciplina. A pesar disso, foi possível a implantação do espaço virtual, que teve modificações após a primeira avaliação dos estudantes, com o objetivo de dar-lhes maior autonomia e protagonismo em seu processo de aprendizagem, feito de modo coletivo e colaborativo. Os estudantes tiveram muita curiosidade e motivação para configurar e montar seus espaços com liberdade. Para conseguir tal objetivo, o estagiário docente teve de colocar todos como administradores, numa clara demonstração de confiança e igualdade entre os atores envolvidos no processo; responder aos questionamentos levantados e motivar a solidariedade do grupo, de modo que aqueles que já tinham conseguido aprender a elaborar e configurar seus espaços deveriam ajudar os demais colegas nas dúvidas. $\mathrm{Na}$ apresentação das pesquisas, os grupos debateram sobre o que cada um tinha compreendido do mundo social à sua volta e das possibilidades de tornarem-se sujeitos ativos na sociedade.

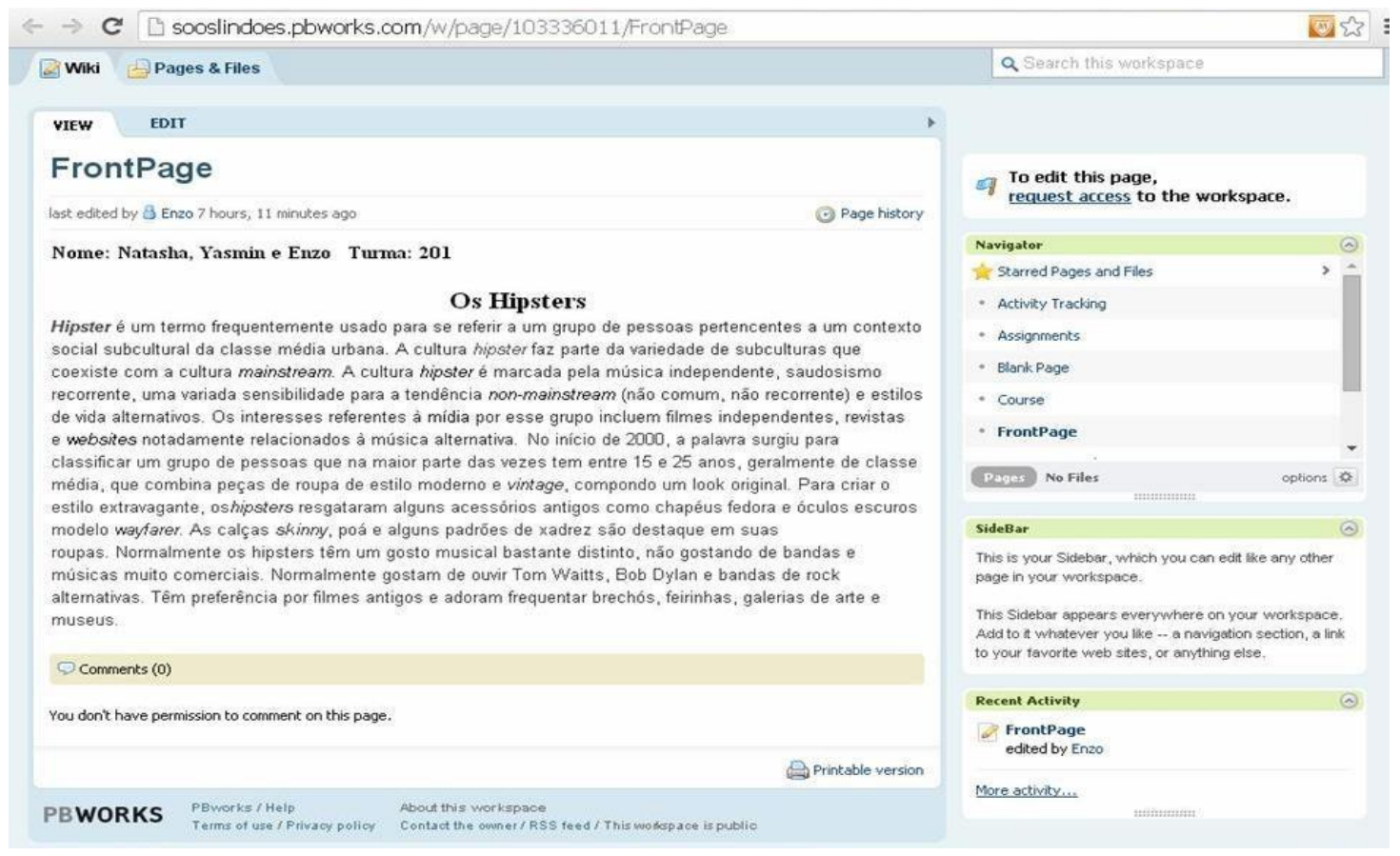

\section{Imagem 3 - Espaço de trabalho criado pelos estudantes da turma 201.}

O que ficou de aprendizado e resultado nessa experiência é que primeiramente, o professor deve ter preparo adequado durante sua formação para fazer uso dos recursos tecnológicos disponíveis ao processo de ensino e aprendizagem. Ele precisa pensar e refletir sobre a forma que deseja aplicar o uso das ferramentas tecnológicas, se simplesmente fazer uma mudança de local e interface, ao trocar a lousa por páginas na Web e fazer os estudantes simplesmente mudarem da escrita em seus cadernos e leitura de livros impressos para a interface gráfica com textos elaborados e caixas de diálogo destinada para os comentários de seus educandos e assim seguir limitados a poucas participações no processo de aprendizagem. Ou então, o docente pode ofertar e explicar o funcionamento do instrumento tecnológico de aprendizagem para motivar e aguçar a 
curiosidade dos estudantes. Por esse caminho, deverá orientar a pesquisa e dar-lhes autonomia de seguirem seus trabalhos de investigação na rede e elaboração de materiais digitais para explicarem, segundo seus pensamentos e visões de mundo social. Como dito por Lévy (1999):

O professor torna-se um animador da inteligência coletiva dos grupos que estão a seu encargo. Sua atividade será centrada no acompanhamento e na gestão das aprendizagens: o incitamento à troca dos saberes, a mediação relacional e simbólica, a pilotagem personalizada dos percursos de aprendizagem, etc. (LÉVY, 1999, p.173)

$\mathrm{Na}$ avaliação da aplicabilidade, deve-se buscar conhecer a infra-estrutura e verificar a viabilidade no uso de recursos computacionais, se a instituição possui pelo menos uma sala ou laboratório de informática. O ideal seria ter mais salas disponíveis com esses recursos porque talvez mais de um docente, das diversas disciplinas, queira fazer uso dos equipamentos nas suas aulas. Mas a realidade de momento é que na maioria das escolas públicas, existe apenas uma sala ou laboratório de informática, e nem todos os docentes são contemplados com o uso desse espaço, da forma como gostariam.

\section{Considerações finais e perspectivas}

No final do estágio, foi feita uma avaliação em conjunto entre professor estagiário e estudantes, com o auxilio de um questionário para investigar a percepção do grupo sobre o uso do PBworks como ferramenta complementar às aulas de Sociologia. As repostas apontaram que essa metodologia de trabalho trouxe benefícios no ensino e aprendizagem de Sociologia e foi além, fazendo com que todos os atores envolvidos na experiência aprendessem mais que somente os temas abordados nas aulas. A sensibilidade do estagiário de perceber a necessidade de mudança frente ao problema abordado por (Bauman, 2009) da crise de atenção para uma dinâmica diferenciada no uso do espaço de trabalho foi fundamental para dar maior autonomia e protagonismo aos estudantes.

Com a sua criação de seus espaços de trabalhos, os estudantes ganharam um local de acesso imediato pelos dispositivos eletrônicos de conexão a rede de dados em qualquer lugar do tempo e espaço aos conteúdos já vistos e os quais ainda seriam abordados, ampliando suas possibilidades de pesquisa e seus espaços para questionamentos e dúvidas.

A outra questão discutida durante o estágio, foi a viabilidade desse espaço vir a ser utilizado em definitivo nas próximas turmas de Sociologia da escola. A pesar das limitações, acredita-se que essa é uma possibilidade bastante interessante para a disciplina, mas que exigiria algumas ações para melhorar seu funcionamento. Além da manutenção da rede de computadores da escola, outra ação importante, seria a elaboração de um trabalho interdisciplinar com a disciplina de língua inglesa, para melhorar a compreensão das instruções necessárias à navegação dentro do PBworks, que são todas em inglês. Também seria interessante a elaboração de um manual informativo, para criar espaços de trabalhos, hipertextos, páginas, pastas e tabelas, editar informações, inserir materiais e navegar pelas páginas do PBworks.

E por último, mais não menos importante, manter o desejo de professor e estudantes de usarem essa ferramenta, no processo de ensino e aprendizagem, por ela 
proporcionar maior interatividade entre todos. Não defendemos aqui que ela substitua as aulas presencias, bem pelo contrário, todas as disciplinas, inclusive a Sociologia, devem e merecem ter mais períodos de aulas para a melhor compreensão dos conteúdos abordados. Enquanto isso não acontece, o espaço é uma alternativa para obter-se um maior contato com o conhecimento sociológico devido ao pouco tempo reservado às aulas presenciais. Devemos aproveitar as possibilidades desses espaços, como descrito na teoria de Vygotski em (La Rosa, 2004), sejam durante o horário reservado as aulas da disciplina ou na visão de (Lévy, 1999) em qualquer local e momento, conectado a internet e às grandes redes que compõem o ciberespaço. 


\section{Referências}

BONA, Aline S. BASSO, M. V. A. Construção de Portifólios de Matemática usando PBworks. Artigo Renote, v.8, n.3, 2010. Disponível em http://seer.ufrgs.br/index.php/renote/article/view/18060/10648 Acesso: 18 Mai. 2015.

BRASIL, Ministério da Educação, Orientações curriculares para o ensino médio: Ciências Humanas e suas tecnologias. Brasília,2006.

BRASIL, Ministério da Educação, Lei de Diretrizes e Bases da Educação Nacional 9394/96, $1996 . \quad$ Disponível em: http://portal.mec.gov.br/seesp/arquivos/pdf/lei9394_ldbn1.pdf Acesso: 18 Out. 2015.

BAUMAN, Zygmunt. A sociedade individualizada: vidas contadas e histórias vividas. Rio de Janeiro, Zahar Editor, 2009.

CASTELLS, Manuel. A Galáxia da Internet: Reflexões sobre a Internet, os Negócios e a Sociedade. Rio de Janeiro, Jorge Zahar Editor, 2003.

KUHN, Thomas. A estrutura das revoluções científicas. São Paulo, Editora Perspectiva, 2001.

LA ROSA, Jorge. Psicologia e educação: O significado do aprender. Porto Alegre, EDIPUCRS, 2004.

LATOUR, Bruno. Reagregando o social. Salvador, Edufba, 2012.

LÉVY, Pierre. Cibercultura. São Paulo, Editora 34, 1999.

MEIRELLES, Mauro et al. O ensino de sociologia no RS: Repensando o lugar da sociologia. Porto Alegre, Editora Evangraf, 2013.

RAMPAZZO, Lino. Metodologia Científica. São Paulo: Editora Loyola, 2004.

SCHÄFER, Patrícia et al. Escrita colaborativa na cultura digital: ferramentas e possibilidades de construção do conhecimento em rede. Artigo Renote, v.7, n.1, 2009. Disponível em: http://seer.ufrgs.br/renote/article/download/14012/7902 Acesso: 17 Out. 2015.

SEIB, Kathia. Como o pbworks pode contribuir na construção do processo de ensino e aprendizagem? 2010. 50 f. Trabalho de Conclusão de Curso de Licenciatura em Pedagogia, Faculdade de Educação da Universidade Federal do Rio Grande do Sul, $2010 . \quad$ Disponível em: http://www.lume.ufrgs.br/bitstream/handle/10183/35723/000795180.pdf?sequence=1 Acesso: 18 Out. 2015.

SILVEIRA, Patrick. O uso do PBworks no ensino de sociologia do ensino médio. 2015. 42 f. Trabalho de Conclusão de Curso de Licenciatura em Ciências Socais, Instituto de Filosofia e Ciências Humanas da Universidade Federal do Rio Grande do Sul, 2015.2 Disponível em: http://www.lume.ufrgs.br/bitstream/handle/10183/139279/000989319.pdf?

sequence=1\&locale-attribute=pt_BR Acesso: 17 Mai. 2016. 